\title{
REVIEW
}

\section{Mitigating nitrous oxide emissions from agricultural soils by precision management}

\author{
Robert M. REES (凶) $)^{1}$, Juliette MAIRE ${ }^{1,2}$, Anna FLORENCE ${ }^{1}$, Nicholas COWAN ${ }^{2}$, Ute SKIBA ${ }^{2}$, \\ Tony van der WEERDEN ${ }^{3}$, Xiaotang $\mathrm{JU}^{4}$ \\ 1 Scotland's Rural College, Edinburgh, Scotland, EH9 3JG, UK \\ 2 Centre for Ecology and Hydrology, Bush Estate, Penicuik, Scotland, EH26 OQB, UK \\ 3 AgResearch, Invermay Agricultural Centre, Mosgiel 9053, New Zealand \\ 4 College of Resources and Environmental Sciences, China Agricultural University, Beijing 100193, China
}

\begin{abstract}
Nitrous oxide $\left(\mathrm{N}_{2} \mathrm{O}\right)$ emissions make up a significant part of agricultural greenhouse gas emissions. There is an urgent need to identify new approaches to the mitigation of these emissions with emerging technology. In this short review four approaches to precision managements of agricultural systems are described based on examples of work being undertaken in the UK and New Zealand. They offer the opportunity for $\mathrm{N}_{2} \mathrm{O}$ mitigation without any reduction in productivity. These approaches depend upon new sensor technology, modeling and spatial information with which to make management decisions and interventions that can both improve agricultural productivity and environmental protection.
\end{abstract}

Keywords decision support systems, mitigation, nitrous oxide, precision farming

\section{Introduction}

There is a growing acceptance that future agricultural production must be fully integrated with the protection of the environment. The requirement to feed humanity as its population rises toward 10 billion, at the same time as living within a safe operating space for a stable and resilient planet, remains a major challenge for society ${ }^{[1]}$. Agriculture is one of the biggest threats to the environment and the development of new approaches to environmental management within agricultural systems is therefore of utmost importance. Nitrous oxide $\left(\mathrm{N}_{2} \mathrm{O}\right)$ is recognized as a powerful greenhouse gas and contributes to the destruction of stratospheric ozone ${ }^{[2]}$. Maintaining agricultural productivity while minimizing $\mathrm{N}_{2} \mathrm{O}$ emissions is a critically

Received July 31, 2019; accepted September 26, 2019

Correspondence: bob.rees@sruc.ac.uk important consideration for the future development of agricultural systems.

Nitrous oxide is a long-lived greenhouse gas with a Global Warming Potential 265-298 times greater than that of carbon dioxide. Around $60 \%$ of anthropogenic sources of this gas are derived from nitrogen fertilizer and manure use in agriculture ${ }^{[3]}$ and the urgent need to reduce greenhouse gas emissions in response to the current threats posed by climate change has highlighted the need to develop new approaches to mitigation. Global emissions are projected to rise by $28 \%$ during the remainder of this century if current trends in population growth and food production continue ${ }^{[4]}$. However, there is significant interest in developing new approaches to mitigation based on the application of new technologies and our increased understanding of source processes. Nitrous oxide is produced by microbial transformations of nitrogen in soils and water. Two main processes are recognized as contributing to emissions, these are nitrification and denitrification $^{[5]}$. The nitrification process involves the oxidation of ammonium to nitrate, involving a group of chemoautotrophic microorganisms. This process occurs rapidly in fertile agricultural soils containing readily available supplies of ammonium nitrogen provided by inputs of fertilizers, manures and crop residues. A small proportion of the nitrogen which is converted from ammonium to nitrate is released as $\mathrm{N}_{2} \mathrm{O}^{[5]}$. A second process contributing to emissions is denitrification which occurs when the nitrate ion is reduced during the process of microbial respiration. Such conditions commonly arise in wet soils containing a plentiful carbon and nitrogen supply ${ }^{[6]}$. In these conditions soil oxygen becomes depleted through respiration and microbes switch to nitrate as a terminal electron acceptor in order to maintain metabolic activity. Although much of the nitrate is reduced to $\mathrm{N}_{2}, \mathrm{~N}_{2} \mathrm{O}$ is produced as an intermediate in these processes. 
In many agricultural soils the processes of nitrification and denitrification occur simultaneously but are strongly influenced by environmental and management controls ${ }^{[6]}$. Soil nitrogen supply, moisture content and temperature are recognized as particularly important factors in influencing emissions $^{[7]}$. However, changes in these factors are highly dynamic and interact strongly with management practices. Nitrogen supply is the most obvious factor controlled by agricultural management through the inputs of fertilizer and manure used to drive crop productivity. Dung and urine deposited by livestock grazing on pastures and forage crops are a further source of $\mathrm{N}$ input. Such inputs can be clearly seen to drive emissions of $\mathrm{N}_{2} \mathrm{O}$, which are often released in significant quantities shortly following fertilizer applications and urine deposition. However, the magnitude of these emissions can be modified by soil conditions and climate at the time of fertilizer application and grazing. Approaches to mitigating $\mathrm{N}_{2} \mathrm{O}$ emissions from soils focus on three main strategies:

(1) Reducing nitrogen inputs or modifying the form in which nitrogen is supplied,

(2) using microbial inhibitors, and

(3) modifying soil conditions by management.

Extensive reviews of approaches to $\mathrm{N}_{2} \mathrm{O}$ mitigation from agricultural systems have been published in recent years using individual approaches described above or a combination of these approaches ${ }^{[8-12]}$. Nitrous oxide emissions from soils are highly heterogeneous in time and space ${ }^{[13]}$. Current approaches to the management of farmland often ignore this heterogeneity, and instead apply uniform management decisions to land, taking no account of variations in the known drivers of emissions. The spatial heterogeneity of $\mathrm{N}_{2} \mathrm{O}$ emissions is often a result of the coincidence of several key driving variables. This often leads to short periods of high $\mathrm{N}_{2} \mathrm{O}$ emissions sometimes two or three orders of magnitude above baseline. However, detailed spatial information that can be collected precisely and temporally with the use of new measurements technology, often at high resolution, can help identify potential hotspots and provide opportunities for intervention to reduce emissions.

In this short review, we focus on the opportunities for precision farming technology to mitigate $\mathrm{N}_{2} \mathrm{O}$ emissions through innovative approaches to soil and crop management. Precision farming uses information and technology to make better management decisions on farms. This technology provides an opportunity to manage heterogeneity in farmland in order to deliver improved productivity, profitability and better environmental outcomes. In recent years there have been very rapid developments in the technology used to deliver precision farming approaches. This includes improvements in sensor technology, satellite observation processing and management of big data and network and communication systems. The question therefore arises whether or not these technologies can be used to reduce greenhouse gas emissions from soils, and if so what evidence is there that this is happening. Here we describe examples of approaches in various stages of development in the UK and New Zealand that may offer opportunities for mitigation.

\section{Precision management of soil pH}

Soil $\mathrm{pH}$ is important in regulating and modifying $\mathrm{N}_{2} \mathrm{O}$ emissions. In more acid soils, there is a higher emission of $\mathrm{N}_{2} \mathrm{O}$ compared to $\mathrm{N}_{2}$ because the $\mathrm{N}_{2} \mathrm{O}$ reductase enzyme that converts $\mathrm{N}_{2} \mathrm{O}$ to $\mathrm{N}_{2}$ is inhibited ${ }^{[14,15]}$. Thus, in soils that have a tendency to produce $\mathrm{N}_{2} \mathrm{O}$ by denitrification, more acid conditions are likely to lead to higher $\mathrm{N}_{2} \mathrm{O}$ emission rates. Given that soil acidity can also reduce crop growth, maintaining soil $\mathrm{pH}$ at an appropriate level is considered important for both the optimization of crop production and efficient use of fertilizer inputs. Lower crop biomass and higher $\mathrm{N}_{2} \mathrm{O}$ emissions in acid conditions can lead to a large increase in $\mathrm{N}_{2} \mathrm{O}$ emission intensity (the quantity of $\mathrm{N}_{2} \mathrm{O}$ produced per unit of crop). New precision approaches to lime application take account of the often large gradients in $\mathrm{pH}$ within fields (Fig. 1), applying lime with variable-rate applicators on a spatial basis according to the lime required to bring soil up to a target $\mathrm{pH}$. Although this management approach is specifically designed to optimize crop growth through $\mathrm{pH}$ management, it is likely that there will be co-benefits in terms of $\mathrm{N}_{2} \mathrm{O}$ mitigation given the sensitivity of emissions to $\mathrm{pH}$. Preliminary measurements highlight the increased emissions of $\mathrm{N}_{2} \mathrm{O}$ in the more acidic areas of grassland (Fig. 1). Work is currently underway at SRUC in the UK in partnership with other European countries and AgResearch in New Zealand to test this hypothesis using conventional and variable-rate lime applications on grassland soils, followed by subsequent measurements of $\mathrm{N}_{2} \mathrm{O}$ emission during the growing season ${ }^{[16]}$.

\section{Managing organic nitrogen inputs}

Organic matter is regularly added to agricultural soils in the form of slurry, manures and animal wastes. Grazing livestock deposit nitrogen rich dung and urine in grassland soils which are recognized as hotspots of greenhouse gas emissions and contribute significantly to the heterogeneity of emissions often observed in these environments ${ }^{[10,17,18]}$. Until recently it has been difficult to characterize the spatial and temporal distribution of these grazing inputs other than through manual observation. However, new remote sensing techniques using high resolution cameras linked to unmanned aerial vehicles (UAVs) is allowing improved understanding of the spatial and temporal patterns of deposition associated with such livestock management. A recent study used image analysis to quantify the appearance of urine patches in an intensively grazed grassland in 

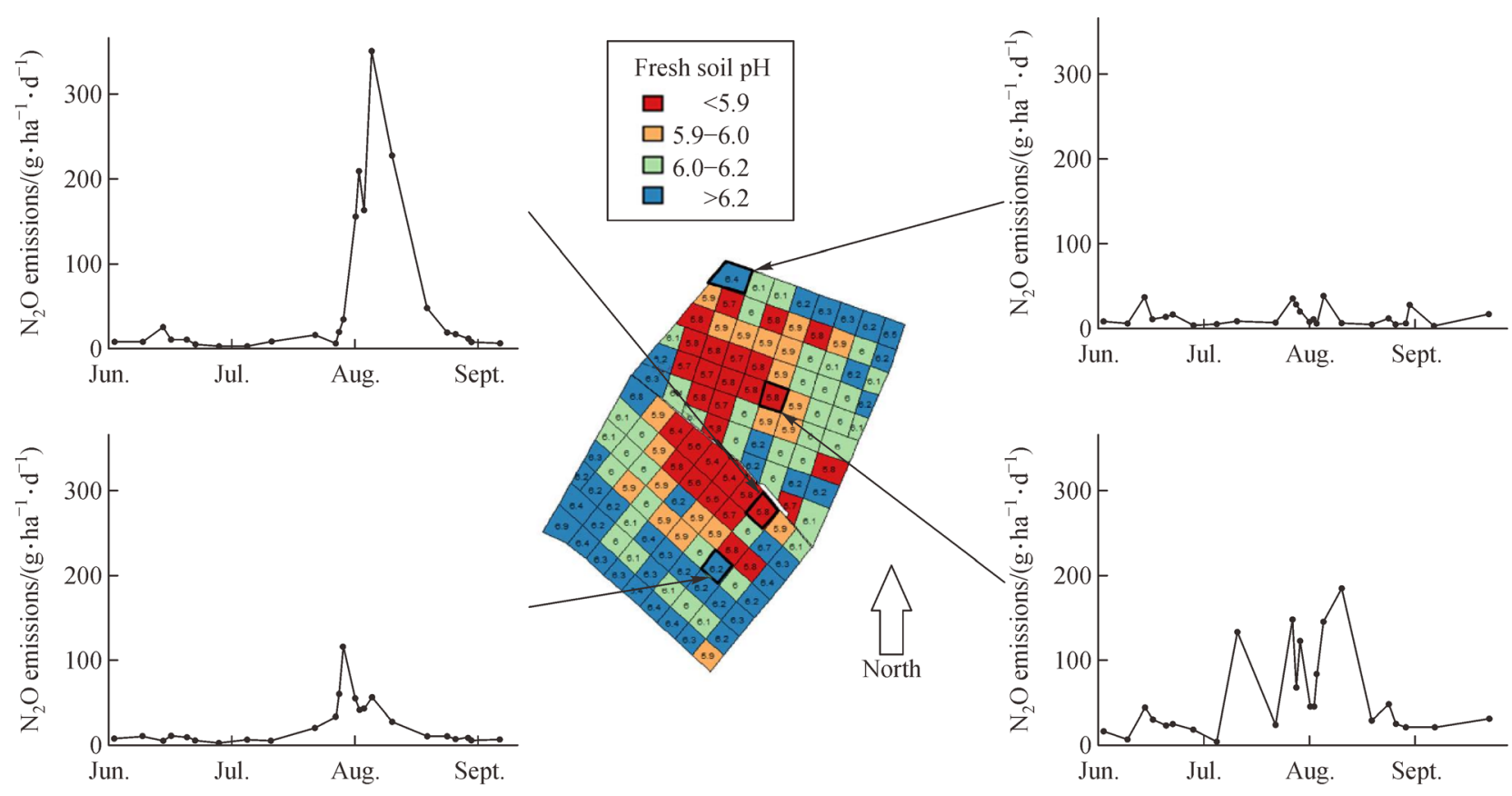

Fig. 1 Spatial heterogeneity of $\mathrm{pH}$ and associated $\mathrm{N}_{2} \mathrm{O}$ emissions from a Scottish grassland soil to a depth of $20 \mathrm{~cm}$ measured on a $10 \mathrm{~m}$ $\times 10 \mathrm{~m}$ grid (each square on the map) at a field site in Easter Bush, Penicuik, Scotland. Measurements of pH performed by Soil Essentials (Angus, Scotland)

Scotland ${ }^{[19]}$. Previous studies have shown that such urine patches contribute to very high emissions of $\mathrm{N}_{2} \mathrm{O}$, which vary throughout the growing season in response to climatic conditions $^{[20,21]}$. By linking the appearance of urine patches to site-specific emission factors it is possible to estimate field scale emissions of $\mathrm{N}_{2} \mathrm{O}$. The opportunity now arises from this work to develop innovative approaches to mitigation. This includes the potential to use UAV technology to deliver urease and nitrification inhibitors to newly formed urine and dung patches within the field. This could have the benefit of minimizing the quantity of inhibitors used, while achieving significant mitigation benefits, both in terms of reduced $\mathrm{NH}_{3}$ and $\mathrm{N}_{2} \mathrm{O}$ emissions. A potential difficulty with this approach is that urine patches only become visible from the second day and can take $5-8 \mathrm{~d}$ to appear. During this period significant emissions of $\mathrm{N}_{2} \mathrm{O}$ can often occur. An alternative approach could therefore use animal based sensors to detect urination events allowing more rapid deployment of inhibitors to points of deposition ${ }^{[22]}$. Another option which has been tried in New Zealand is to monitor soil changes in soil electrical conductivity and use this as a proxy for the detection of urine patches ${ }^{[23]}$. Mapping urine patches in this way could allow early intervention and application of inhibitors in order to reduce $\mathrm{N}_{2} \mathrm{O}$ emissions. Another potential benefit of this approach would be to use it in order to adjust mineral fertilizer applications, using spatial maps of urine deposition by livestock to adjust the inputs of mineral fertilizer through variable-rate fertilizer applications.

\section{Decision support tools to reduce $\mathrm{N}_{2} \mathrm{O}$ emissions in grazing systems}

An alternative approach to $\mathrm{N}_{2} \mathrm{O}$ mitigation in grazed grasslands is to remove livestock from grazing areas when environmental conditions exceed threshold values that are known to be associated with emission peaks. This approach has been used in a modeling study in New Zealand to assess potential reductions in $\mathrm{N}_{2} \mathrm{O}$ emissions and wider environmental benefits of removing cattle from grazing areas during periods of excess wetness ${ }^{[24]}$. The approach involves monitoring when soil wetness exceeds a soil-specific threshold value above which large emissions of $\mathrm{N}_{2} \mathrm{O}$ could be anticipated. Under these conditions, duration-controlled grazing is implemented where cattle are moved from the pasture to a holding yard, an area of land with a pine bark and sawdust base. A comparison of the whole system emissions (which assessed total $\mathrm{N}_{2} \mathrm{O}$ and manure-derived $\mathrm{CH}_{4}$ emissions) was made between current typical practice (100\% in-paddock grazing, apart from milking time) and implementation of durationcontrolled grazing. For the latter, grazing time was either 0 (i.e., complete removal), 13 or $17 \mathrm{~h} \cdot \mathrm{d}^{-1}$. The analysis showed that in poorly drained soils removal of cattle from the grazing area could achieve up to $12 \%$ reduction in total $\mathrm{N}_{2} \mathrm{O}$ and manure-derived $\mathrm{CH}_{4}$ emissions, much of which was associated with reduced emissions from the $\mathrm{N}_{2} \mathrm{O}$ released from urine and dung. There were ancillary benefits both in poor and imperfectly drained soils 
associated with reduced nitrate leaching. A further advantage of management interventions of this type is associated with reductions in soil damage associated with compaction, which is particularly prevalent under wet conditions. Practical applications of this approach require further testing, but the results to date suggest a costeffective and environmentally beneficial approach to greenhouse gas mitigation, particularly for farmers with poorly drained soils.

\section{Variable-rate nitrogen fertilizer application in cropping systems}

Improving the synchrony between fertilizer nitrogen applications and crop demand has long been recognized as a potential approach to reducing nitrogen losses from cropping systems ${ }^{[25]}$. In most current systems, crops obtain a significant proportion of their nitrogen supply from the mineralization of soil organic matter which is then supplemented by the addition of fertilizer nitrogen. However, the supply of nitrogen across a field from mineralization can be highly variable, and this is rarely considered when planning fertilizer application. Remote sensing techniques now offer the opportunity to monitor crop growth and development at increasingly high resolutions. Canopy reflectance can be used as a measure of the nitrogen concentrations in crop tissues and fertilizer recommendations can be adjusted to take into account of this variability in crop nitrogen content across a field ${ }^{[26]}$. Often this involves a system with sensors mounted on the front of a tractor which observe crop nitrogen reflectance and converts this into an index of crop nitrogen uptake and then adjusts the nitrogen fertilizer addition according to whether the uptake is above or below a threshold value. Advancements are being made in using satellite imagery to detect canopy reflectance ${ }^{[27,28]}$. Improvements in image resolution and visit intervals have the potential to increase the scale and temporal resolution of monitoring for targeted fertilizer applications, allowing targeted timing of interventions alongside altering fertilizer amounts on a spatial basis.

In some circumstances suboptimal nitrogen uptake is associated with poor soil conditions such as compaction, low soil organic matter concentrations or restricted soil depth. In these circumstances additional fertilizer nitrogen inputs may well exacerbate nitrogen losses rather than increase crop nitrogen recovery. A more sophisticated approach would look at variations in soil nitrogen supply across a field that could be directly linked to differences in mineralization of nitrogen, and then adjust nitrogen supply in accordance with this variation. Where soil conditions limit nitrogen recovery it would be more appropriate to either improve soil conditions, for example, through alleviating compaction, or in circumstances where this is not possible, to reduce fertilizer nitrogen applications. Any improvements in the recovery of crop $\mathrm{N}$ that can be achieved by precision management of this kind are likely to lead directly to a reduction in $\mathrm{N}_{2} \mathrm{O}$ in emissions, given the strong link between nitrogen supply and emissions that has been characterized in many previous studies ${ }^{[7,29,30]}$.

\section{Conclusions}

This short review has provided several examples of how precision management of agricultural systems can potentially be used to reduce $\mathrm{N}_{2} \mathrm{O}$ emissions from soils. As we develop improved spatial and temporal knowledge of the farmed landscape, further opportunities will be developed that can support more efficient resource use with reduced environmental impacts. These approaches have yet to be widely adopted in agricultural systems and are still in the process of development, but they offer significant promise given their capacity to maintain or increase productivity while reducing environmental impacts. Solutions will involve the analysis of large data sets describing the farmed environment coupled with a modeling framework that encapsulates our understanding of the transformation of nitrogen in the environment, and linked eventually to decision support tools that will aid farmers and land users to make better decisions about crop management and environmental protection.

Acknowledgements The authors thank the funders of this work, including the Scottish Government Strategic Research Programme, N-Circle project (BB/N013484/1) and Teagasc in Ireland. The New Zealand study was funded by the New Zealand Government through the Global Research Alliance.

Compliance with ethics guidelines Robert M. Rees, Juliette Maire, Anna Florence, Nicholas Cowan, Ute Skiba, Tony van der Weerden, and Xiaotang $\mathrm{Ju}$ declare that they have no conflicts of interest or financial conflicts to disclose.

This article does not contain any studies with human or animal subjects performed by any of the authors.

\section{References}

1. Griggs D, Stafford-Smith M, Gaffney O, Rockström J, Ohman M C, Shyamsundar P, Steffen W, Glaser G, Kanie N, Noble I. Sustainable development goals for people and planet. Nature, 2013, 495(7441): 305-307

2. IPCC. Climate Change 2013: the Physical Science basis. Contribution of working group I to the Fifth Assessment Report of the Intergovernmental Panel on Climate Change. In: Stocker T F, Qin D, Plattner G K, Tignor M, Allen S K, Boschung J, Nauels A, Xia Y, Bex B, Midgley B M, eds. Cambridge and New York: Cambridge University Press, 2013, 1535

3. Reay D S, Davidson E A, Smith K A, Smith P, Melillo J M, Dentener F, Crutzen P J. Global agriculture and nitrous oxide emissions. Nature Climate Change, 2012, 2(6): 410-416

4. Fowler D, Steadman C E, Stevenson D, Coyle M, Rees R M, Skiba 
U M, Sutton M A, Cape J N, Dore A J, Vieno M, Simpson D, Zaehle S, Stocker B D, Rinaldi M, Facchini M C, Flechard C R, Nemitz E, Twigg M, Erisman J W, Butterbach-Bahl K, Galloway J N. Effects of global change during the 21 st century on the nitrogen cycle. Atmospheric Chemistry and Physics, 2015, 15(2): 1747-1868

5. Butterbach-Bahl K, Baggs E M, Dannenmann M, Kiese R, Zechmeister-Boltenstern S. Nitrous oxide emissions from soils: how well do we understand the processes and their controls? Philosophical Transactions of the Royal Society of London. Series B: Biological Sciences, 2013, 368(1621): 20130122

6. Zhu G, Song X, Ju X, Zhang J, Müller C, Sylvester-Bradley R, Thorman R E, Bingham I, Rees R M. Gross N transformation rates and related $\mathrm{N}_{2} \mathrm{O}$ emissions in Chinese and UK agricultural soils. Science of the Total Environment, 2019, 666: 176-186

7. Rees R M, Augustin J, Alberti G, Ball B C, Boeckx P, Cantarel A, Castaldi S, Chirinda N, Chojnicki B, Giebels M, Gordon H, Grosz B, Horvath L, Juszczak R, Klemedtsson A K, Klemedtsson L, Medinets S, Machon A, Mapanda F, Nyamangara J, Olesen J E, Reay D S, Sanchez L, Cobena A S, Smith K A, Sowerby A, Sommer M, Soussana J F, Stenberg M, Topp C F E, van Cleemput O, Vallejo A, Watson C A, Wuta M. Nitrous oxide emissions from European agriculture - an analysis of variability and drivers of emissions from field experiments. Biogeosciences, 2013, 10(4): 2671-2682

8. de Klein C A M, van der Weerden T J, Luo J, Cameron K C, Di H J. A review of plant options for mitigating nitrous oxide emissions from pasture-based systems. New Zealand Journal of Agricultural Science, 2019 [Published Online]. doi: 10.1080/ 00288233.2019 .1614073

9. Hénault C, Grossel A, Mary B, Roussel M, Leonard J. Nitrous oxide emission by agricultural soils: a review of spatial and temporal variability for mitigation. Pedosphere, 2012, 22(4): 426-433

10. Luo J, Wyatt J, van der Weerden T J, Thomas S M, de Klein C A M, Li Y, Rollo M, Lindsey S, Ledgard S F, Li J, Ding W, Qin S, Zhang N, Bolan N, Kirkham M B, Bai Z, Ma L, Zhang X, Wang H, Liu H, Rys G. Chapter five - potential hotspot areas of nitrous oxide emissions from grazed pastoral dairy farm systems. Advances in Agronomy, 2017, 145: 205-268

11. Mosier A, Kroeze C, Nevison C, Oenema O, Seitzinger S, van Cleemput $\mathrm{O}$. Closing the global $\mathrm{N}_{2} \mathrm{O}$ budget: nitrous oxide emissions through the agricultural nitrogen cycle. Nutrient Cycling in Agroecosystems, 1998, 52(2-3): 225-248

12. Rees R M, Baddeley J A, Bhogal A, Ball B C, Chadwick D R, MacLeod M, Lilly A, Pappa V A, Thorman R E, Watson C A, Williams J R. Nitrous oxide mitigation in UK agriculture. Soil Science and Plant Nutrition, 2013, 59(1): 3-15

13. Cowan N J, Norman P, Famulari D, Levy P E, Reay D S, Skiba U M. Spatial variability and hotspots of soil $\mathrm{N}_{2} \mathrm{O}$ fluxes from intensively grazed grassland. Biogeosciences, 2015, 12(5): 15851596

14. Liu B, Frostegård Å, Bakken L R. Impaired reduction of $\mathrm{N}_{2} \mathrm{O}$ to $\mathrm{N}_{2}$ in acid soils is due to a posttranscriptional interference with the expression of nosZ. mBio, 2014, 5(3): e01383-14

15. Qu Z, Wang J, Almøy T, Bakken L R. Excessive use of nitrogen in Chinese agriculture results in high $\mathrm{N}_{2} \mathrm{O} /\left(\mathrm{N}_{2} \mathrm{O}+\mathrm{N}_{2}\right)$ product ratio of denitrification, primarily due to acidification of the soils. Global Change Biology, 2014, 20(5): 1685-1698
16. Dorsch P. Mitigating Agricultural Greenhouse Gas Emissions by improved $\mathrm{pH}$ management of soils. FACCE ERA-GAS Monitoring and mitigation of Greenhouse gases from agri- and silvi-culture, 2017. Available at FACCE ERA-GAS website on September 1, 2019

17. Bell M J, Rees R M, Cloy J M, Topp C F, Bagnall A, Chadwick D R. Nitrous oxide emissions from cattle excreta applied to a Scottish grassland: effects of soil and climatic conditions and a nitrification inhibitor. Science of the Total Environment, 2015, 508: 343-353

18. Chadwick D R, Cardenas L M, Dhanoa M S, Donovan N, Misselbrook T, Williams J R, Thorman R E, McGeough K L, Watson C J, Bell M, Anthony S G, Rees R M. The contribution of cattle urine and dung to nitrous oxide emissions: quantification of country specific emission factors and implications for national inventories. Science of the Total Environment, 2018, 635: 607617

19. Maire J, Gibson-Poole S, Cowan N, Reay D S, Richards K G, Skiba U, Rees R M, Lanigan G J. Identifying urine patches on intensively managed grassland using aerial imagery captured from remotely piloted aircraft systems. Frontiers in Sustainable Food Systems, 2018, 2: 10

20. van der Weerden T J, Manderson A, Kelliher F M, de Klein C A M. Spatial and temporal nitrous oxide emissions from dairy cattle urine deposited onto grazed pastures across New Zealand based on soil water balance modelling. Agriculture, Ecosystems \& Environment, 2014, 189: 92-100

21. van Groenigen J W, Velthof G L, van der Bolt F J E, Vos A, Kuikman P J. Seasonal variation in $\mathrm{N}_{2} \mathrm{O}$ emissions from urine patches: effects of urine concentration, soil compaction and dung. Plant and Soil, 2005, 273(1-2): 15-27

22. Dennis S J, Moir J L, Cameron K C, Edwards G R, Di H J. Measuring excreta patch distribution in grazed pasture through lowcost image analysis. Grass and Forage Science, 2013, 68(3): 378385

23. Bates G, Quin B F, Bishop P. Low-cost detection and treatment of fresh cow urine patches. Palmerston North New Zealand: Massey University, 2015, Occasional Publication No. 28

24. van der Weerden T J, Laurenson S, Vogeler I, Beukes P C, Thomas S M, Rees R M, Topp C F E, Lanigan G, de Klein C A M. Mitigating nitrous oxide and manure-derived methane emissions by removing cows in response to wet soil conditions. Agricultural Systems, 2017, 156: $126-138$

25. Diacono M, Rubino P, Montemurro F. Precision nitrogen management of wheat. A review. Agronomy for Sustainable Development, 2013, 33(1): 219-241

26. Chen Z Q, Wang L, Bai Y L, Yang L P, Lu Y L, Wang H, Wang Z Y. Spectral response of maize leaves and prediction of their nitrogen content. Spectroscopy and Spectral Analysis, 2013, 33(4): 10661070

27. Clevers G J, Kooistra L, van den Brande M M. Using Sentinel-2 data for retrieving LAI and leaf and canopy chlorophyll content of a potato crop. Remote Sensing, 2017, 9(5): 405

28. Clevers G J, Gitelson A A. Remote estimation of crop and grass chlorophyll and nitrogen content using red-edge bands on Sentinel-2 and -3. International Journal of Applied Earth Observation and 
Geoinformation, 2013, 23: 344-351

29. Bouwman A F, Boumans L J M, Batjes N H. Emissions of $\mathrm{N}_{2} \mathrm{O}$ and NO from fertilized fields: summary of available measurement data. Global Biogeochemical Cycles, 2002, 16(4): 6-1-6-13
30. Song X, Liu M, Ju X, Gao B, Su F, Chen X, Rees R M. Nitrous oxide emissions increase exponentially when optimum nitrogen fertilizer rates are exceeded in the North China Plain. Environmental Science \& Technology, 2018, 52(21): 12504-12513 